Research Journal of Applied Sciences 13 (4): 229-234, 2018

ISSN: $1815-932 \mathrm{X}$

(C) Medwell Journals, 2018

\title{
The Role of Alpha-1 Antitrypsin Enzyme on Pulmonary Dysfunction Due to Exposure to $\mathrm{NO}_{2}$
}

\author{
${ }^{1}$ Satria Pratama, ${ }^{1}$ Bambang Wispriyono, ${ }^{1}$ Haryoto Kusnoputranto and ${ }^{2}$ Faisal Yunus \\ ${ }^{1}$ Department of Environmental Health, Faculty of Public Health, \\ ${ }^{2}$ Department of Pulmonology and Respiratory Medicine, Faculty of Medicine, \\ Universitas Indonesia, Depok, Indonesia
}

\begin{abstract}
Nitrogen dioxide $\left(\mathrm{NO}_{2}\right)$ is one of the air pollutants whose concentration is increasing due to the increased number of vehicles as a mode of transportation. Exposure to $\mathrm{NO}_{2}$ causes physical symptoms of respiratory disorders and lung function and Alpha 1 Antitrypsin (AAT) plays a role in the protection of inflammation due to exposure to $\mathrm{NO}_{2}$ through inactivation by nitrogen. This study aims to reveal the relationship of $\mathrm{NO}_{2}$ exposure, AAT and lung function of the traffic police in Jakarta. It is a cross sectional study with 112 traffic police as research subjects divided into two groups: the police working on the highway and working in the office. $\mathrm{NO}_{2}$ measurement of the environment is carried out at the location where the subjects work and examination is done toward lung physiology, AAT levels, body weight, body fat percentage, height and waist circumference as a factor in determining lung function. $\mathrm{NO}_{2}$ levels are $18.72 \mathrm{ppb}$ on highways (high exposure areas) and $4.14 \mathrm{ppb}$ in the office (low exposure area), respectively. There are $49 \%$ of the traffic police working on the highway (high exposure to $\mathrm{NO}_{2}$ ) and $51 \%$ of police officers working in the office (low exposure to $\mathrm{NO}_{2}$ ). Mean of pulmonary physiology, represented by percentage of FVC (Forced Vital Capacity), on the entire subject is 89.49 and mean of $\mathrm{FEV}_{1}$ (Forced Expiratory Volume in $1 \mathrm{sec}$ ) is 95.39. The mean of FEV compared to FVC is 88.4 and there is no significant difference between police officers working in the highway and working in the office. AAT levels in both subjects show normal values compared to normal levels of AAT standard of $141.07 \mathrm{mg} / \mathrm{dL}$. Finally, the prediction model obtained in the end which is the prediction of FVC percentage and $\mathrm{FEV}_{1}$ percentage for both the dependent variable has a normal distribution. In conclusion, the value of lung function for police officers working on the roads is lower than the value of lung function of those working in the office. Factors that affect lung function in this study are $\mathrm{NO}_{2}$ levels, AAT, fat, age (35 years old), visceral fat and waist circumference.
\end{abstract}

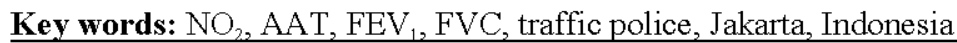

\section{INTRODUCTION}

Air pollution can occur indoors (indoor pollution) and outside (outdoor pollution). Outdoor pollution is generally caused by pollution from motor vehicle fumes in dustrial, marine and natural processes of living beings. Sources of air pollutants can be classified into stationary sources and mobile sources and those can develop of COPD (Ko and Hui, 2012). Nitrogen dioxide $\left(\mathrm{NO}_{2}\right)$, Sulfur dioxide $\left(\mathrm{SO}_{2}\right)$ and Carbon monoxide $(\mathrm{CO})$ are examples of air pollutant dangerous at room temperature. $\mathrm{NO}_{2}$ exposure levels were found to be significantly associated with distance of residence from a main road and vehicle utilization (Hong et al., 2005). High intensity exposure to $\mathrm{NO}_{2}$ in a confined space could result in serious injury including death. Exposure to $\mathrm{NO}_{2}$ at room temperature increases the risk of respiratory infections through the interaction of pollutants with the immune system
(Chen et al., 2007). High concentrations of $\mathrm{NO}_{2}$ in urban areas with high population of motor vehicles will cause or aggravate asthma, cough, respiratory diseases reactive airway inflammation and chronic respiratory disease (Fields, 2004) and genetic association studies have been the most feasible study design for investigating the interactions between genetics and the adverse effects of air pollutants in humans (Yang et al., 2008).

Nitrogen dioxide is an air pollutant that is influential in generating emphysematous like lesions in the lungs of animals. Despite pathogenesis processes that generate these lesions is still unclear, the mechanism includes the possibility similar to the occurrence of emphysema in smokers. The occurrence of emphysema is due to degradation of the alveoli rich in elastin as the result of uncontrolled proteolysis due to endogenous elastase. Enzymes $\alpha 1$-proteinase inhibitor have a major role in controlling the activity of neutrophil elastase

Corresponding Author: Bambang Wispriyono, Department of Environmental Health, Faculty of Public Health, 
(Johnson et al., 1990). Mohsenin and Gee are also conducting studies to measure the activity of the enzyme $\alpha 1$-proteinase inhibitor obtained from BAL fluid (Broncho Alveolar Lavage) on the subject of non-smokers exposed to $\mathrm{NO}_{2}$ for $3 \mathrm{~h}$ at a dose of 3-4 ppm and then do the bronchial rinse $3-4 \mathrm{~h}$ after exposure to $\mathrm{NO}_{2}$. The results of this study found $\mathrm{NO}_{2}$ causes $45 \%$ reduction of enzyme activity of $\alpha 1$-proteinase inhibitor. This decrease makes neutrophil elastase destroy elastin in the alveoli (Mohsenin and Gee, 1987). $\alpha 1$-proteinase inhibitor are also plays important role in smoking induced emphysema (Evans and Pryor, 1994).

Alpha 1 Antitrypsin (AAT) could prove to be an important marker protein in the exacerbation of COPD (Koczulla et al., 2012) and there is significant associations between spirometric decline rate acceleration and AAT deficiency severity in FDNY workforce during the first 4 years after WTC-related inhalation injury (Banauch et al., 2010). AAT deficiency is closely related to the occurrence of pulmonary emphysema appearing at the age of $35-45$ years is chronic as progressive fatigue and other non-specific symptoms. AAT deficiency is often associated with the PI ZZ genotype and very rarely with the PI SZ genotype. In addition, to AAT deficiency, patients with PI ZZ genotype are patients with other genotypes such as PI MZ and PI MM. Patients with Chronic Obstructive Pulmonary Disease (COPD) with the PI MZ genotype experience a decrease in lung function faster than COPD patients with the PI MM genotype (Serres and Blanco, 2014). Sorheim et al. (2010) conduct a case study (COPD Patients post $\mathrm{BD} \mathrm{FEV}_{1} / \mathrm{FVC}<0.7$ and $\mathrm{FEV}_{1}<80 \%$ predicted) with the number of 834 patients and control (Patients with normal spirometer) with the number of 835 patients. The result is that PI MZ is the predictor for the low ratio of $\mathrm{FEV}_{1} / \mathrm{FVC}$. Based on multivariate analysis, PI MZ has a ratio of $\mathrm{FEV}_{1} / \mathrm{FVC} 3.5 \%$ lower compared to PI MM; PI MZ is more susceptible to the development of airway obstruction interference than PI MM (Sorheim et al., 2010).

The purpose of this study is to determine the levels of $\mathrm{AAT}, \mathrm{NO}_{2}$ levels of workplace air and pulmonary function impairment and determine factors most influential to lung function of traffic police. This study covers the environment $\mathrm{NO}_{2}$ levels, AAT levels and value of lung function (Forced vital capacity and forced expiratory volume in $1 \mathrm{sec}$ ) on the traffic police in Jakarta.

\section{MATERIALS AND METHODS}

Based on the research objectives, the research uses cross sectional study design. Cross sectional assess exposure and the status of a disease or disorder as an outcome simultaneously at one time. This design is used for research that is not reported routinely and requires measurements to identify cases. Data on the incidence of health is the prevalence or the proportion of people in a population affected by the outcome (Heederik and Teschke, 2005). Epidemiological research environment put a cross sectional view to determining the sample with high exposure group and compared with external comparators (low exposure group) (Baker, 2008).

The study assesses $\mathrm{NO}_{2}$ levels, AAT levels and the environment as the main independent variable. All of these variables will be assessed simultaneously at one time to assess the magnitude of the problems that exist in the population. Therefore, the cross-sectional design is the most appropriate design to answer the purposes of this study. The study is conducted on a specific group of community with regard to exposure where the selection of the study population is carried out by exposure status police officers working on the roads or highways as a group of high exposure and those working in the office as the external comparison. The study uses a calculation of different sample mean and obtains 52 samples for each group and the total sample of 112. At the time of the sampling in terview, the measurement of height, weight, body fat, visceral fat, body mass index and spirometry as well as blood sampling for checking levels of the enzyme AAT is done.

\section{RESULTS AND DISCUSSION}

Different characteristics of the subject between the low exposure group and high exposure group covers average levels of $\mathrm{NO}_{2}$, gender, age, height, weight, BMI (Body Mass Index), waist circumference, fat, visceral fat, levels of AAT can be seen in Table 1. The results of the independent variable characteristics between the two groups all have non-significant difference except the fat variables and levels of the enzyme of AAT.

This study obtain spirometry test results to determine lung function as dependent variables between low exposure and high exposure group as shown in

Table 1: Characteristics of the independent variables between low exposure

\begin{tabular}{llll}
\multicolumn{4}{c}{ group and high exposure group } \\
\hline Variables & Exposed & Low exposed & p-values \\
\hline $\mathrm{NO}_{2}$ levels (ppb) & 18.72 & 4.14 & 0.398 \\
$\mathrm{Sex}(\mathrm{N}(\%))$ & - & - & 0.000 \\
Male- & $54(100)$ & $43(76.8 \%)$ & - \\
Female & $0(0 \%)$ & $13(23.2 \%)$ & - \\
Age (average (year)) & $37.55(8.58)$ & $39.01(9.47)$ & 0.399 \\
Height (cm) & 169.4 & 169 & 0.678 \\
Weight (kg) & 81.0 & 81.9 & 0.714 \\
Body nass (kg/m $\left.{ }^{2}\right)$ & 28.2 & 28.6 & 0.618 \\
index & & & \\
Waist (cm) & 96.6 & 93.5 & 0.202 \\
circumference & & & \\
Fat (\%) & 25.9 & 28.7 & 0.007 \\
Visceral fat & 14.0 & 13.6 & 0.688 \\
Alpha 1 anti & 151.9 & 130.6 & 0.002 \\
trypsin (mg/dL) & & &
\end{tabular}


Table 2: Different lung functions between low exposure group and high

\begin{tabular}{|c|c|c|c|c|}
\hline $\begin{array}{l}\text { Dependent } \\
\text { variable }(\%)\end{array}$ & $\begin{array}{c}\text { High } \\
\text { exposure }\end{array}$ & $\begin{array}{c}\text { Low } \\
\text { exposure }\end{array}$ & p-values & K-S test \\
\hline FVC & 88.6 & 90.2 & 0.449 & 0.20 \\
\hline $\mathrm{FEV}_{1}$ & 94.5 & 96.1 & 0.500 & 0.20 \\
\hline $\mathrm{FEV}_{1} / \mathrm{FVC}$ & 87.8 & 88.9 & 0.416 & 0.00 \\
\hline FEF 2575 & 115.6 & 115.0 & 0.905 & 0.20 \\
\hline APE & 69.1 & 79.2 & 0.006 & 0.02 \\
\hline
\end{tabular}

Table 3: Correlation of the dependent variable with normal distribution toward variables

\begin{tabular}{lcc}
\hline & Dependent variable & \\
& $-\mathrm{FEV}_{1}(\%)$ & $\mathrm{FCV}(\%)$ \\
Independent variables & & \\
Age & -0.006 & -0.182 \\
r & 0.951 & 0.057 \\
P & & \\
Fat & -0.217 & -0.286 \\
r & 0.023 & 0.002 \\
P & & \\
BMI & -0.209 & -0.303 \\
r & 0.029 & 0.001 \\
P & & \\
Visceral fat & -0.178 & -0.315 \\
r & 0.063 & 0.001 \\
P & & \\
\hline
\end{tabular}

Table 2. Pulmonary function tests between the 2 groups result in non-significant different except for the variable Peak Expiratory Flow (PEF). In Table 2, it can also be seen the value of Kolmogorov-Smirnov (K-S test) to see the data distribution of the dependent variable. K-S test on variables of $\mathrm{FEV}_{1}, \mathrm{FVC}, \mathrm{FEF} 2575$ (Forced Expiratory Flow) shows a normal distribution.

Correlation test on the dependent variable with normal distribution of lung function shows that only age variable has a non-significant correlation (Table 3). Overall, the independent variables have negative correlation with lung function seen with R-values that all are negative. Figure 1 shows a scatter plot graph on the correlation of independent variables with normal distribution on lung function. Variables percentage of fat and body mass index although, significant shows a weak correlation against the percentage of $\mathrm{FEV}_{1}$ $(-0.217$ and -0.209$)$ and the percentage of FCV (-0.286 and -0.303). Variable visceral fat has a significant correlation but the correlation is very weak against the percentage of $\mathrm{FEV}_{1}(-0.178)$ and $\mathrm{FCV}(-0.315)$.

Multivariate analysis performed in this study aims to look at the most decisive factor of lung function for police officers working on highways. The primary independent variable is the concentration of $\mathrm{NO}_{2}$ that represents the condition of two locations: in the office and the environment. The other variable as priority is AAT. Variable AAT has a curve sloping to the left and the results of Kolmogorov-Smirnov test is $\mathrm{p}=0.00$, thus, modification by changing the AAT into 1/AAT variable. The 1/AAT variable has a curve sloping to the right of the
Kolmogorov-Smirnov test and $\mathrm{p}=0.002$. The dependent variable used of lung function is the percentage of FCV and $\mathrm{FEV}_{1}$, both have a normal distribution in the normality test so they can be analyzed using linear regression method.

The first stage is to find the regression of the dependent variable $\mathrm{FEV}_{1}$. Variable of $\mathrm{NO}_{2}$ levels is still included in the linear regression test because the levels of $\mathrm{NO}_{2}$ is the most important independent variable and $1 / \mathrm{AAT}$ variable is still included as a major independent variable because it is part of the research hypothesis. The independent variable of age is replaced with categorical variables of age groups on dichotomous nominal variables such as age $>35$ years old and $<35$ years old. The result of the analysis is:

$$
\begin{aligned}
\mathrm{FEV}_{1}(\%)= & 126.643-0.198 \times \mathrm{NO}_{2}-179.824 \times(1 / \mathrm{AAT}) \\
& -0.413 \times(\text { fat })-0.76 \times(\text { age } 35)+0.204 \times \\
& (\mathrm{VF})-0.196 \times(\mathrm{LP})
\end{aligned}
$$

Discussions include data collection, laboratory analys is, relationship of $\mathrm{NO}_{2}$ exposure with some of the factors that will affect lung function and limitations of the study. Problems that arise are all police officers (whether working in the office or on the highways) still have an obligation to work on the highways at least twice a month, so, it will be difficult to find research subjects that have never served in the traffic. Sampling of the ambient $\mathrm{NO}_{2}$ is carried out according to rush hour traffic to get results of maximum $\mathrm{NO}_{2}$ levels. Blood sampling for AAT test does not experience problems because blood taken is the blood serum, stored in the refrigerator so it does not lyse. The results of all blood samples could be examined. Two subjects are excluded because after examination and interview, one had a history of chronic diseases and one is a new officer, so, the total subjects who successfully enrolled in the study are 110 people with a composition of 56 people in the office and 54 subjects on highways.

The examination on the level of ambient $\mathrm{NO}_{2}$ is done using Griess Saltzman method with a spectrophotometer. The results show that $\mathrm{NO}_{2}$ levels are higher on highways than in the office with a value of 18.72 and $4.14 \mathrm{ppb}$. Although, the environmental data obtained seem high, this data is far below the threshold value set by Jakarta Province's Environment Agency (BPLHD) at $400 \mathrm{ppb}$. Indonesia's threshold value is the same as the threshold value set in Europe (Sandström, 1995). The threshold value for the measurement of 1 hour in Indonesia is much higher than that set by the US to the region of US, i.e, . 200 ppb (Anonymous, 2008). 
Res. J. Applied Sci., 13 (4): 229-234, 2018
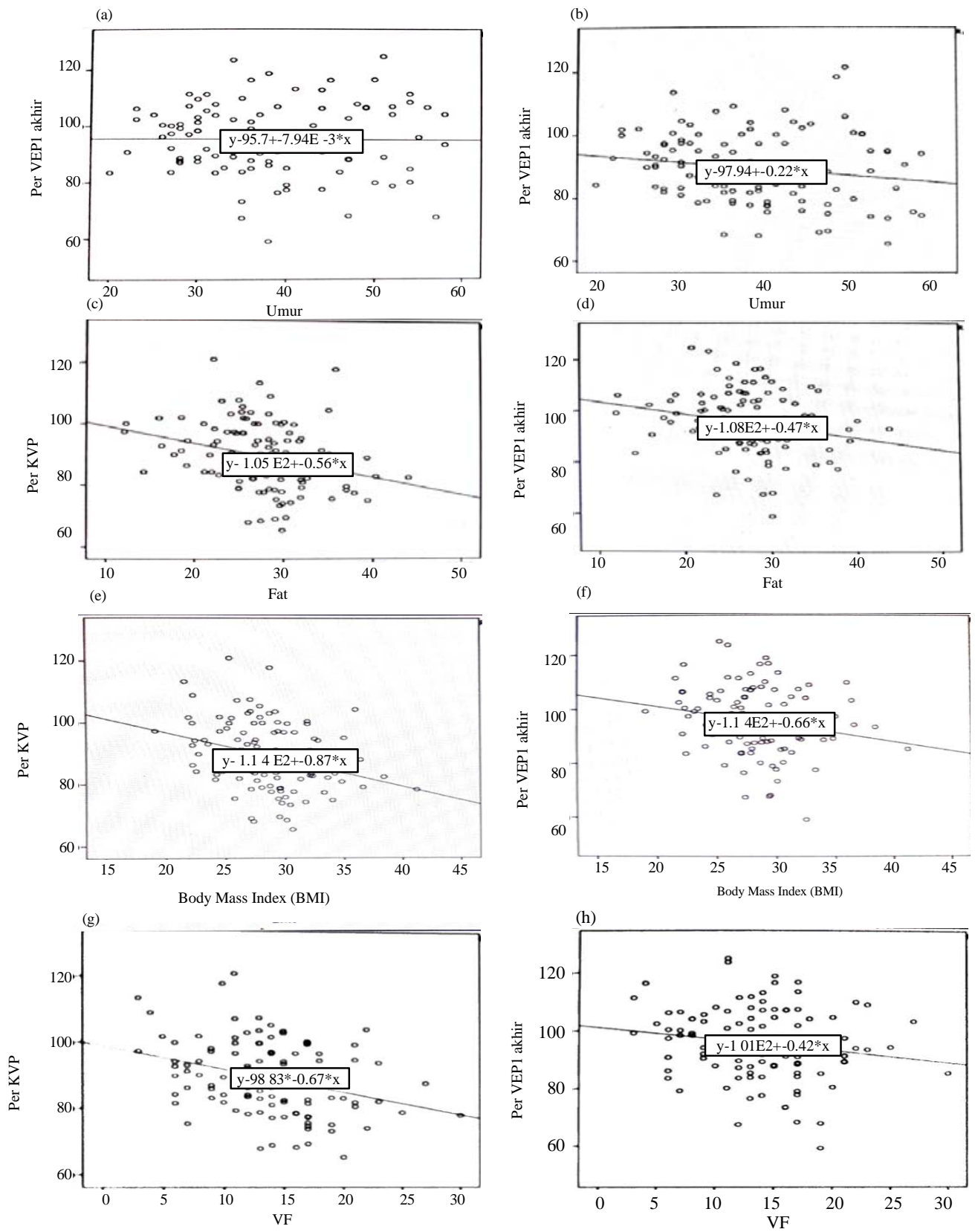

Fig. 1: a) R, linear-3519E-S; b) R, linear-0033; c) R, linear-0.082; d) R, linear-0.047; e) R, linear-0.092;f) R, linear-0.044; g) $\mathrm{R}$, linear-0.099; $\mathrm{h}$ ) $\mathrm{R}$, linear-0.032; A scatter plot graph on the correlation of independent variables (age, fat, body mass index and visceral fat) with normal distribution on lung function

Forced Vital Capacity (FVC) is a value to determine disruptions of lung restriction. FVC value is a parameter to determine pulmonary function to know abnormalities in restriction or lung development. This value is also used as a comparison of the value of Forced Expiratory Volume in $1 \mathrm{sec}\left(\mathrm{FEV}_{1}\right)$ to determine airway obstruction (Dermawan and Yunus, 2013). Forced vital capacity percent value in this study shows no significant difference between subjects exposed to high exposure and low exposure even though the average value for the high exposure group is lower than the low exposure group 88.68 and 90.27 . These results differ from those by Prashant Patil and others who conduct research on traffic police and police officers working in an office that there is significant difference between the high exposure group and the low exposure group at 77 and 88.8 (Patil et al., 
2013). The different results of forced vital capacity between the two groups in the present study could occur because the mean for variables theoretically associated with forced vital capacity values such as height, weight, waist circumference and age do not differ significantly between the two groups.

$\mathrm{FEV}_{1}$ is important to know how much obstruction (respiratory disorders) that occurs. The results of the research show a mean value of $\mathrm{FEV}_{1}$ percentage between groups exposed to high and low exposure is not significant although the mean value of $\mathrm{FEV}_{1}$ percentage in the high exposure group is lower. $\mathrm{FEV}_{1}$ value is quite important because the symptoms are often directly from gas exposure on the respiratory tract. Results obtained if categorized based on the obstruction disorder by dividing the normal value of $\mathrm{FEV}_{1}$ percentage $>80 \%$ and $\mathrm{FEV}_{1}$ percentage $<80 \%$ among high exposure and low exposure group is $5(9.2 \%)$ and $6(10.7 \%)$ person. The two groups based on the test results are not significantly different.

There are significant differences among subjects exposed to high and low exposure to the levels of alpha 1 anti-trypsin. The mean levels of alpha 1 anti-trypsin on the subjects of high exposure have higher values $151.91 \mathrm{mg} / \mathrm{dL}$ than subjects exposed to low exposure 130.62. Although, there are differences in the mean levels of alpha 1 anti trypsin, both are still within the normal limit of more than $80 \mu \mathrm{g} / \mathrm{mL}$. Examination using ELISA to determine levels of alpha 1 anti-trypsin as a diagnostic uses normal limit value of $80 \mathrm{mg} / \mathrm{dL}$ (Mulgrew et al., 2007). The determination of this standard is different from the study conducted by Amin. Amin conducts a study on patients and employees of a factory as many as 418 subjects with the lowest levels determined $180 \mathrm{mg} / \mathrm{dL}$ Amin, 2001). Johnson et al. (1990) conduct a study in healthy people exposed to $\mathrm{NO}_{2}$ and control group (without $\mathrm{NO}_{2}$ ) for $3 \mathrm{~h}$ in a random test double blind on the subjects and then continues with bronchoalveolar rinse with bronchoscopy to measure the activity of the enzyme alpha 1 proteinase inhibitor (alpha 1 antitrypsin) on liquids of bronchoalveolar lavage. The study shows strong evidence in the inactivation of inhaled AAT in low levels of $\mathrm{NO}_{2}$ in the short term although it still needs further studies to determine the inhibition of AAT in $\mathrm{NO}_{2}$ repeated exposure (Johnson et al., 1990). The unique susceptibility of AAT-deficient individuals to exposure to chemicals and particulate environmental agents (De Serres, 2003) may also affected the result of AAT level in this study.

Determining factors that are most instrumental in lung function in this study is done using multivariate analysis without neglecting the essence of variables. After the selection of candidates and co-linearity, candidates will be tested in multivariate analyses. The results in this study show that multivariate test cannot be done ideally to get the parsimony model. The results of multivariate analysis in determining the value of $\mathrm{FEV}_{1}$ percentage show that for every increase of 1 value of $\mathrm{NO}_{2}$ will affect $19.8 \%$ of $\mathrm{FEV}_{1}$. The explanation also applies in assessing the other variables in the model. These results such in studies by Park et al. (2012) assessing factors of body composition on lung function in 291 healthy subjects with fat percentage are the most significant factor in determining the impairment of $\mathrm{FEV}_{1}$, although, in conclusion Park et al. (2012) state that predictions based on factors of body composition is not quite comprehensive in explaining the condition and to replace the standard lung function prediction formula today.

Monitoring biological processes is one of the three preventive devices of diseases caused by toxic materials and working environment in general as well as two other matters related to the environment and health monitoring or surveillance. The third stage of the presence of ambient concentrations of pollutants in air, water and food will finally reach the fourth stage, i.e., the dose of contaminants that enter the human body. The second stage and third stage can be done with the dynamics and mechanisms of transport. The third and fourth stage can be done by looking at the pattern of past exposure on human beings. The emergence of effect stage is undesirable health disorders. It depends on the dose response. Our previous study also showed one malondialdehyde as one of stress oxidative marker in pulmonary function of chromium's exposed workers (Wispriyono et al., 2016). These studies have reached stage 3 and it still takes two more stages to determine whether exposure to $\mathrm{NO}_{2}$ have an adverse effect on health, so, it is difficult to conclude a single causality of $\mathrm{NO}_{2}$ as factors causing disruption of lung function on police officers working on highways. Endogenous NO could also influence the mechanism. NO endogenous can be increased by regulating the proinfalamtory mediators and AAT play a role in inhibiting cell activation and suppressing cytokine production which associated with proinflamatory stimulation (Chan et al., 2012).

\section{CONCLUSION}

The ambient $\mathrm{NO}_{2}$ levels obtained in this study on highways (high exposure areas) is higher compare with in the office (low exposure area), although, it is not significantly different. However, the value of lung function for police officers working on the roads is lower than the value of lung function of those working in the office and the levels of AAT is statistically significant. The factors affecting lung function of $\mathrm{FEV}_{1}$ percentage for officers working on highways based are the levels of $\mathrm{NO}_{2}, \mathrm{AAT}$, visceral fat and waist circumference. 


\section{ACKNOWLEDGEMENTS}

The reseacrher gratefully acknowledges the Universitas of Indonesia for providing financial support for partly of this research through Universitas Indonesia's Internationally-Index's Publication Competency Grant Research (Hibah Kompetensi Publikasi International Terindeks Universitas Indonesia), 2016 No. 2517/UN2.R12/HKP.05.00/2016.

\section{REFERENCES}

Amin, M., 2001. The role of alpha-1-antitrypsin in generating chronic obstructive pulmonary disorder. Respirology, 6: S39-S43.

Anonymous, 2008. Risk and exposure assesment to support the review of the $\mathrm{NO} 2$ primary national ambient air quality standard. Environment Protection Department, United States Environmental Protection Agency, Washington, D.C., USA. https:/www3.epa.gov/ttn/naaqs/standards/nox/dat a/20081121_NO2_REA_final.pdf

Banauch, G.I., M. Brantly, G. Izbicki, C. Hall and A. Shanske et al, 2010. Accelerated spirometric decline in New York City firefighters with al-antitrypsin deficiency. Chest J., 138: 1116-1124.

Chan, E.D., G.B. Pott, P.E. Silkoff, A.H. Ralston and C.L. Bryan et al., 2012. Alpha-1-antitrypsin inhibits nitric oxide production. J. Leukocyte Boil., 92: 1251-1260.

Chen, T.M., W.G. Kuschner, J. Gokhale and S. Shofer, 2007. Outdoor air pollution: Nitrogen dioxide, sulfur dioxide and carbon monoxide health effects. Am. J. Med. Sci., 333: 249-256.

De Serres, F.J., 2003. Alpha-1 antitrypsin deficiency is not a rare disease but a disease that is rarely diagnosed. Environ. Health Perspect., 111: 1851-1854.

Dermawan, R. and F. Yunus, 2013. [Fixed rate diagnostic test against normal lower limit VEP1/KVP for assessing breath channel obstruction (In Indonesian)]. J. Respir. Indo., 33: 210-220.

Evans, M.D. and W.A. Pryor, 1994. Cigarette smoking, emphysema and damage to alphal-proteinase inhibitor. Am. J. Physiol. Lung Cell Mol. Physiol., 266: L593-L611.

Fields, S., 2004. Global nitrogen: Cycling out of control. Environ. Health Perspect., 112: A556-A563.

Heederick, D. and K. Teschke, 2005. Exposure Assessment for Pesticides in Epidemiological Studies. In: Occupational and Residential Exposure Assessment for Pesticides, Franklin, C.A. J.P. Worgan (Eds.). John Wiley \& Sons, Hoboken, New Jersey, USA., pp: 245-274.
Hong, Y.C., J.H. Leem, K.H. Lee, D.H. Park and J.Y. Jang et al., 2005. Exposure to air pollution and pulmonary function in university students. Intl. Arch. Occup. Environ. Health, 78: $132-138$.

Johnson, D.A., M.W. Frampton, R.S. Winters, P.E. Morrow and M.J. Utell, 1990. Inhalation of nitrogen dioxide fails to reduce the activity of human lung alpha-1-proteinase inhibitor. Am. Rev. Respir. Dis., 142: 758-762.

Ko, F.W. and D.S. Hui, 2012. Air pollution and chronic obstructive pulmonary disease. Respirology, 17 : 395-401.

Koczulla, A.R., S. Noeske, C. Herr, J. Koepke and R.A. Jorres et al., 2012. Alpha-1 antitrypsin is elevated in exhaled breath condensate and serum in exacerbated COPD patients. Respir. Med., 106: $120-126$.

Mohsenin, V. and J.B.L. Gee, 1987. Acute effect of nitrogen dioxide exposure on the functional activity of alpha-1-protease inhibitor in bronchoalveolar lavage fluid of normal subjects. Am. J. Respir. Crit. Care Med., 136: 646-650.

Mulgrew, A.T., C.C. Taggart and N.G. McElvaney, 2007. Alpha-1-antitrypsin deficiency: Current concepts. Lung, 185: 191-201.

Park, J.E., J.H. Chung, K.H. Lee and K.C. Shin, 2012. The effect of body composition on pulmonary function. Tuberculosis Respire. Dis., 72: 433-440.

Patil, P.J., G.V. Thakaer and S.P. Patil, 2013. Comparative study of lung function test of policemen in traffic control with those in general duty. Natl. J. Physiol. Pharm. Pharmacol., 3: 162-166.

Sandstrom, T., 1995. Respiratory effects of air pollutants: Experimental studies in humans. Eur. Respir. J., 8: 976-995.

Serres, F.D. and I. Blanco, 2014. Role of alpha-1 antitrypsin in human health and disease. J. Internal Med., 276: 311-335.

Sorheim, I.C., P. Bakke, A. Gulsvik, S.G. Pillai and A. Johannessen et al., 2010. al-Antitrypsin protease inhibitor MZ heterozygosity is associated with airflow obstruction in two large cohorts. Chest J., 138: 1125-1132.

Wispriyono, B., R. Kurniawan, R. Novirsa, B. Hartono and M. Sari, 2016. Pulmonary function and Malondialdehyde (MDA) content in blood due to chromium exposure among tannery workers in Sukaregang, Garut. Res. J. Environ. Toxicol., 10: 183-188.

Yang, I.A., K.M. Fong, P.V. Zimmerman, S.T. Holgate and J.W. Holloway, 2008. Genetic susceptibility to the respiratory effects of air pollution. Thorax, 63: $555-563$. 